\title{
A CRISE DO CAPITAL E A REDEFINIÇÃO DO PAPEL DO ESTADO COMO PROVEDOR DE POLÍTICAS PÚBLICAS EDUCACIONAIS
}

\author{
Adriana de Jesus Diniz FARIAS \\ Pedagoga e Mestranda em Educação/PPGED/ICED/UFPA \\ drika-diniz@hotmail.com
}

Resumo: Neste artigo abordaremos a redefinição do Estado a partir da crise do capital e as consequentes mudanças nas políticas públicas educacionais, não só no que concerne ao seu financiamento como principalmente a sua concepção. O texto tem por objetivo apontar as causas da atual crise na educação e salientar a responsabilidade do neoliberalismo nos rumos que tomou a educação no Brasil. A análise centra-se na revisão de estudos de autores que pesquisam acerca dos efeitos do neoliberalismo na educação. Concluimos que as políticas públicas educacionais adotadas pelo Estado estão voltadas para a lógica do neoliberalismo com a racionalização de recursos, entre outros fatores.

Palavras-chave: Crise do capital. Reforma do estado. Política educacional.

Abstract: In this article we discuss the redefinition of the state from the crisis of capital and the resulting changes in public policies in education, not only regarding its financing mainly to its design. The text aims to pinpoint the causes of the current crisis in education and emphasize the responsibility of neoliberalism in the direction that education has taken in Brazil. The analysis focuses on a review of studies of authors who research on the effects of neoliberalism in education. It is concluded that the educational policies adopted by the State are directed to the logic of neoliberalism with the rationalization of resources, among other factors.

Keywords: Crisis of capital. State of reform. Education politics.

\section{Introdução}

Vivemos a crise do capital ou a crise do Estado? Quem são os culpados por estas supostas crises? A culpa pela crise da educação é do capital ou do Estado? Que implicações a nova morfologia do trabalho traz para a educação? Qual a saída para a crise da qualidade da educação? O que fazer para superar esta crise? 
Perguntas como estas cercam nosso imaginário ao estudarmos o neoliberalismo, a reforma do Estado e o atual quadro da educação no Brasil.

Segundo Antunes (2001), nos últimos quarenta anos, ocorreram sucessivas transformações do capital. O século XX é a era da degradação do trabalho, pois, após o esgotamento do modelo taylorista-fordista, ou seja, da produção e do consumo em massa, vivemos hoje a era da máxima financeirização da economia e da produção, em que a lógica do mercado é ao mesmo tempo vender e financiar. A informalização e a terceirização traduzem a nova morfologia do trabalho - o toyotismo -, na qual o intelecto se converteu em mercadoria.

Nesse sentido, a educação é vista também como mercadoria, pois as políticas públicas educacionais, adotadas pelo Estado, estão voltadas para a lógica do neoliberalismo.

\section{Liberalismo e neoliberalismo}

De acordo com Morais (2001), a partir de 1776, com a publicação de $A$ riqueza das nações, de Adam Smith, a economia ganhou um novo modelo de atuação, a doutrina liberal, em que se pregava a necessidade de desregulamentar e privatizar as atividades econômicas, ou seja, reduzir as funções do Estado na economia. Para Smith, as funções do governo se restringiam à manutenção da segurança interna e externa do país; à garantia da propriedade e dos contratos e à responsabilidade por serviços essenciais de utilidade pública. Além disso, salienta a importância da livre iniciativa na economia:

Smith afirma que o mundo seria melhor - mais justo, racional, eficiente e produtivo - se houvesse a mais livre iniciativa, se as atitudes econômicas dos indivíduos e suas relações não fossem limitadas por regulações e monopólios garantidos pelo estado e pelas corporações de oficio (MORAIS, 2001, p. 13).

O liberalismo, doutrina que se movia contra as instituições reguladoras do feudalismo, contra as corporações de oficio e contra o Estado mercantilista, defende que o mercado é a melhor saída para o sucesso: 
Mais uma vez afirma-se que o mercado é o melhor caminho para gerar eficiência, justiça e riqueza. Eficiência, porque propicia o uso mais eficaz das potencialidades proporcionadas pela natureza, distribui o trabalho de modo mais econômico. Justiça, já que, pelo aumento de volume de produtos, difunde-se o beneficio. Os resultados da liberdade econômica são a paz e a harmonia internacional (MORAIS, 2001, p. 16).

Porém, há um movimento contra este progresso, são os regulamentos estatais, ou seja, a política econômica dirigista do mercantilismo e as corporações (sindicatos). Tais regulamentações eram amparadas pela legislação. $\mathrm{Na}$ Inglaterra, por exemplo, vigoravam as Leis dos Pobres, Lei dos Aprendizes e a Lei do Domicílio, leis estas que regulamentavam materiais, técnicas, preços, monopólios, mão de obra etc. Havia um excesso de regulamentações que acabavam por impedir os aperfeiçoamentos na indústria.

De acordo com Morais (2001), além disso, Smith dizia que as corporações eram outro meio de regulamentar a economia, pois baixavam normas duras referentes à mão de obra, salário, emprego, aprendizagem, assistência. O governo regulamentava a existência de corporações. Em suma, a tradição liberal baseia-se em dois grandes princípios: a procura do interesse próprio conduz ao ajustamento entre os indivíduos e a uma determinada harmonização dos diferentes esforços e vontades; e o poder político deve ser cuidadosamente limitado pela lei.

Morais (2001, p. 28) afirma que "o século XIX foi também coroado por severas crises de superprodução, pânicos financeiros e pela disputa de grandes potências na corrida para dominar impérios neocoloniais. Suas primeiras décadas foram marcadas por guerras continentais e sucessivas revoluções. Esse clima fortaleceria o tema da 'rebelião de massas"”.

Neste cenário político, econômico e social emerge a doutrina keynesiana, com a publicação da "Teoria geral do emprego, do juro e da moeda”, de John Maynard Keynes, em 1936. Segundo essa doutrina, “o Estado deveria planejar grandezas macroeconômicas sobre as quais era possível acumular conhecimento e controle prático. O poder público desse modo regularia as oscilações de emprego e investimentos, moderando as crises econômicas e sociais" (MORAIS, 2001, p. 31). 
Segundo o mesmo autor, já o neoliberalismo tem sua inauguração com Hayek, em 1944, com a publicação de "O caminho da servidão". Esse livro opunha-se aos socialistas e posicionava-se contra qualquer política econômica ou social regulamentadora. $\mathrm{O}$ neoliberalismo inaugura o retorno do liberalismo.

Consolidava-se, então, segundo Morais, "um novo mundo político, marcado pela negociação entre corporações empresariais e proletárias, intermediadas e institucionalizadas pelo poder público" (p. 31). O retorno do liberalismo viria então a partir da metade dos anos 70 , quando programas neoliberais tomaram poder: com Margaret Thatcher, na Inglaterra, em 1980; com Reagan, nos Estados Unidos, em 1982; e com Helmut Kohl, na Alemanha. Esta nova doutrina representa um ataque às formas de regulação econômica, ao socialismo, ao keynesianismo, ao estado de bem-estar social, ao terceiro-mundismo e ao desenvolvimento latino-americano. Segundo o neoliberalismo, a sobrecarga do Estado levava à ingovernabilidade das democracias, e para solucionar tal problema supunham "limitar a participação política, distanciar a sociedade e o sistema político, subtrair as decisões administrativas ao controle político" (MORAIS, 2001, p. 16).

\section{A reforma do Estado}

As principais ideias neoliberais para reformar o Estado são privatizar empresas estatais e serviços públicos e transferir ao setor privado as atividades produtivas. A privatização prega também a transferência das atividades sociais para a iniciativa privada. Lembrando que os "grandes males" do Estado intervencionista eram a regulação legislativa. O Estado transforma-se em instrumento de grupos de pressão e ocorre o crescimento das despesas públicas e da tributação. Isso, para os neoliberais, causa a crise da eficácia e da produtividade. Sua salvação viria com a globalização financeira, com a liberação da economia mundial, com a internacionalização das atividades econômicas, pois estas limitam a ação do Estado. "A ideologia neoliberal prega o desmantelamento das regulações produzidas pelos Estados nacionais” (MORAIS, 2001, p. 39).

Segundo Morais (2002), as narrativas neoliberais oferecem explicações para a crise e alternativas para a sua superação. Suas causas 
estariam nos problemas derivados das políticas sociais, pois os custos crescentes, os efeitos destrutivos e os resultados desastrosos acentuavam a crise. Em contrapartida, a superação da crise estava na hegemonia do mercado como mecanismo de alocação de recursos, de distribuição de bens, serviços e rendas e como remunerador dos empenhos e engenhos. O mercado configura-se como base da riqueza, da eficiência e da justiça, sendo que a intervenção estatal sobre a economia deve ser controlada legalmente, pois acabam por desviar recursos das atividades produtivas para atividades improdutivas.

As narrativas neoliberais, segundo Morais, desenvolvem uma forte retórica contra o estado de bem-estar social, em que é preciso "exorcizar" a democracia de massas, restringir e equilibrar os orçamentos. A Reforma do Estado viria com a libertação da máquina estatal e do universo da democracia representativa, com a luta contra a entrada das massas na vida política e da limitação do sufrágio.

Além disso, a ideia de privatizar, ou seja, transferir para o privado o bem público ou sua administração e de terceirizar significavam descentralizar a deliberação coletiva, gestão e contratação flexíveis, ajustes permanentes na duração e na qualidade do trabalho, vínculo estrito entre salário e desempenho, individualizações das remunerações, percursos profissionais não padronizados, além de núcleos gestores mais ou menos enxutos.

Segundo Peroni (2006, p. 11), "para a teoria neoliberal não é o capitalismo que está em crise e sim o Estado. A estratégia, portanto é reformar o Estado ou diminuir sua atuação para superar a crise. $\mathrm{O}$ mercado é que deverá superar as falhas do Estado; assim a lógica do mercado deve prevalecer inclusive no Estado para que ele possa ser mais eficiente e produtivo".

Porém, para autores como Meszáros, Antunes e Harvey, ocorre uma crise estrutural do capital. "Para Antunes (1999), a crise do fordismo-keynesianismo era a expressão fenomênica de uma crise estrutural do capital propiciada por uma tendência decrescente na taxa de lucros" (PERONI, 2006, p. 12-13). "Para a terceira via, o Estado deve repassar as políticas sociais para a sociedade, através do Terceiro Setor; para o Neoliberalismo, deve transferi-las para o mercado, através das privatizações" (PERONI, 2006, p. 17). 
O Terceiro Setor entendido como atividades públicas desenvolvidas por particulares, ainda segundo esta autora, o "Terceiro Setor multiplicouse em um contexto de crise do estado-Providencia, período em que o neoliberalismo tem como objetivo fundamental a desregulamentação da economia, tentando retirar o poder do Estado para esvaziar o poder do voto" (PERONI, 2006, p. 19).

O plano de Reforma do Estado no Brasil pode ser evidenciado neste trecho de Peroni:

No plano de Reforma do Estado as políticas sociais foram consideradas serviços não exclusivos do Estado e, assim sendo, de propriedade pública não estatal ou privada. As estratégias de Reforma do Estado no Brasil são: a privatização, a publicização e a transferência (PERONI, 2006, p. 21).

\section{A crise do capital e a educação}

Segundo Gentili, após a ditadura militar, os países da América Latina que estavam quebrados economicamente foram tomados pela expansão do neoliberalismo. "A partir da aplicação de um conjunto de reformas orientadas para garantir um rigoroso programa de ajuste econômico como produto da chamada crise da dívida" (GENTILI, 1998, p. 13).

Os organismos internacionais, como o FMI e o Banco Mundial, preocupados com o pagamento da enorme dívida externa dos países da América Latina, impuseram uma política de descentralização, ou seja, de eliminação das políticas sociais por meio do neoliberalismo, assim poderiam destinar mais recursos para pagar a dívida, ao mesmo tempo reproduzi-la. Este é o chamado Consenso de Washington, que formulou um conjunto de dez recomendações: disciplina fiscal (ou seja, cortar gastos); redefinição das prioridades do gasto público (necessidades de planejamento estratégico); reforma tributária; liberalização do setor financeiro (com circulação do capital sem barreiras, ou seja, sem impostos); manutenção de taxas do câmbio repetitivas (estabilização da moeda); liberação comercial; atração de aplicações de capital estrangeiro; privatização de empresas estatais; desregulação da economia; proteção de direitos autorais. 
Salienta-se que foi necessário um conjunto de regras da eloquência para legitimar o "consenso". Na educação, a gestão baseada na predominância dos técnicos, ou seja, importância do aspecto técnico em detrimento do social.

Segundo Gentili (1998), na visão neoliberal, a educação latinoamerica enfrenta uma crise de eficiência, eficácia e produtividade. A expansão acelerada da oferta educacional durante a segunda metade do século produziu uma progressiva deterioração da qualidade. A América Latina estaria passando por uma profunda crise de gestão das políticas educacionais. Segundo o neoliberalismo, o Estado é incapaz de gerir políticas sociais. Assim, é necessário "transferir a educação da esfera política para a esfera do mercado, negando sua condição de direito social e transformando-a em uma possibilidade de consumo individual, variável segundo o mérito e a capacidade dos consumidores" (GENTILI, 1998, p. 19).

\section{As implicações da nova ordem econômica para a educação}

$\mathrm{Na}$ educação, o processo de Reforma do Estado pode ser percebido a partir da descentralização das atribuições do Estado para o público não estatal mediante vários programas e projetos, como o Programa Brasil Alfabetizado, as creches comunitárias, o Planfor, o PDDE etc.

A partir do "Consenso de Washington" e de suas "recomendações", vimos, nas palavras de GENTILI, "uma redução progressiva do gasto público" e uma "crescente" diminuição dos gastos de capital (com a consequente deterioração das condições de infraestrutura dos sistemas). Gentili enfatiza:

O Consenso de Washington abre muitas interrogações acerca das possibilidades estratégicas de uma alternativa democrática para o neoliberalismo. De qualquer maneira, também nos apresenta algumas claras evidências. Uma delas é fundamental para concluir o presente capítulo: depois do dilúvio neoliberal, nossas escolas serão muito piores do que já são agora (GENTILI, 1998, p. 35).

Tais recomendações foram ditadas por organismos internacionais como o Banco Mundial e o Fundo Monetário Internacional. O BM 
apresenta um pacote de medidas para a reforma da educação de primeiro grau nos países em desenvolvimento. Na América Latina, especificamente no Brasil, seus efeitos estão mais no sentido de produzir ineficiência, má qualidade do ensino e desigualdade no sistema escolar, pois nas palavras de Rosa Maria Torres "as políticas e estratégias recomendadas pelo BM contêm serias fragilidades na sua conceituação e fundamentação" (TORRES, 2000, p. 127), ou seja, tais políticas estão potencializando discursos e práticas excludentes.

Segundo Torres, no pacote de reforma do BM destacam-se como elementos distintivos: a prioridade depositada sobre a educação básica; a melhoria da qualidade (e da eficiência) da educação como eixo da reforma educativa; a prioridade sobre os aspectos financeiros e administrativos da reforma educativa; a descentralização (descentralização de quê?) e instituições escolares autônomas e responsáveis por seus resultados; a convocação para maior participação dos pais e da comunidade nos assuntos escolares; o impulso do setor privado e dos organismos não governamentais (ONGs) como agentes ativos no terreno educativo, tanto nas decisões como na implementação; a mobilização e a elaboração eficaz de recursos adicionais para a educação de primeiro grau; um enfoque setorial; e a definição de políticas e prioridades baseadas na análise econômica.

De acordo com Torres, o BM propõe políticas para melhorar as práticas educacionais, as quais seriam: melhorar o currículo efetivo; proporcionar livros didáticos e guias didáticos para os professores; estabelecer, manter e controlar um tempo fixo de instrução; formação docente em serviço (continua programas curtos, visitas e intercâmbios, educação a distancia etc.); uso do rádio interativo como sistema de ensino na sala de aula (como complemento ou substituto do docente); uso de instrução programada (com indicações detalhadas passo a passo); complemento nutricional por meio de merenda escolar ou de pequenos lanches; identificação e tratamento de outros problemas de saúde (infecções parasitárias, problemas de visão e de audição); educação pré-escolar (particularmente para os setores menos favorecidos). Porém, estas políticas, no entendimento de Torres, supõem "uma proposta que contribui para reforçar, em vez 
de modificar, as tendências predominantes no sistema educativo e na cultura escolar convencionais" (p. 176).

Ideia que é reforçada ainda nesta passagem:

Há um mecanismo do funcionamento do Banco Mundial que se vincula ao Fundo Monetário Internacional muito claramente: sem o aval do Fundo, não há possibilidade de se estabelecer negociações com o Banco. Isto é importante porque muitos economistas têm falado no 'consenso de Washington' como uma das forças que impõem a lógica do ajuste estrutural no mundo (TORRES, 1995, p. 124).

Torres lembra Coraggio, quando diz que "devido [ao] fato de o Banco Mundial ser composto primordialmente por economistas e não educadores, o objetivo final seria a eficiência econômica, a liberdade de mercados e a globalização do capital, com o qual um dos resultados é a supervalorização das medidas quantitativas do 'êxito' de uma política” (TORRES, 1995, p. 127).

Para concluir a ideia de Torres, evidenciamos este parágrafo:

De fato, as prioridades ditadas pela lógica econômica parecem não coincidir com as prioridades propostas pela construção de um modelo educativo legitimamente centralizado na qualidade e na equidade, autenticamente comprometido com a aprendizagem e com sua melhoria. Supõe um enfoque sistêmico da educação, uma visão de longo prazo, uma estratégia de mudança muito mais radical do que o BM parece disposto a sustentar e apoiar. Supõe reverter, em vez de reforçar, as prioridades e as ênfases tradicionalmente conferidas no setor educativo, colocar a escola efetivamente no centro, partir dela mais que 'cair de paraquedas' nela, contar com os professores como interlocutores e atores privilegiados da reforma educativa.

Em suma, na visão neoliberal, o sistema educacional deve se converter em um mercado, e o caminho para a saída da crise é consultar quem melhor entende de mercado, os empresários, por isso a justificativa para se "consultar" tais organismos internacionais.

\section{5}




\section{Considerações finais}

Autores preocupados com a precarização do trabalho, como Ricardo Antunes, defendem a tese de que a crise está no capitalismo e não no Estado e que isso traz implicações nas relações de produção, ou seja, no trabalho. A crise estrutural do capitalismo, por ser um modelo super explorador, chega a um momento em que não há consumidores, e o sistema entra em crise. O padrão de acumulação fordista-taylorista entra em crise. Além disso, a nova morfologia do trabalho, com a informalização e a terceirização, produzem uma maior flexibilização, em que se tem descompromisso com as leis trabalhistas, além da desregulamentação do trabalho, com contratos terceirizados e temporários.

Outro aspecto levantado pelos autores anteriormente citados é o fato de que, na visão neoliberal, o estado de bem-estar social intervindo na economia e sendo responsável pelas políticas públicas quebra a máquina. É necessário tornar tudo mercadoria e todos consumidores. Aí se inclui a educação; vemos então a sua mercantilização.

Os organismos internacionais estão preocupados mais com o pagamento da dívida externa pelos países devedores do que com a melhoria da qualidade da educação. Suas políticas não traduzem mudanças significativas e sim reforçam a reprodução das desigualdades, conforme ideias explicitadas por Torres.

Portanto, a crise do capital e a redefinição do papel do Estado como provedor de políticas educacionais têm se caracterizado como reprodução de uma falsa democracia e de uma falsa melhoria na qualidade da educação, pois a lógica adotada na educação dos países em desenvolvimento é a lógica do capitalismo, no que concerne à mercantilização de tudo, o que produz e reproduz as desigualdades econômicas e sociais.

\section{REFERÊNCIAS}

ANTUNES, Ricardo. Trabalho e precarização numa ordem neoliberal. In: GENTILI, Pablo; FRIGOTTO, Gaudêncio (Org.). A cidadania negada: política de exclusão na educação e no trabalho. $2^{\mathrm{a}}$ ed. São Paulo: Cortez; Buenos Aires: CLACSO, 2001.

GENTILI, P. O consenso de Washington e a crise da educação na América Latina. In: GENTILI, P. A falsificação do consenso: simulacro e 
imposição na reforma educacional do neoliberalismo. Petrópolis: Vozes, 1998. p. 13-39.

MORAES, Reginaldo. Neoliberalismo: de onde vem para onde vai? São Paulo: ed. SENAC, 2001.

MORAES, R. C. Reformas neoliberais e políticas públicas: hegemonia ideológica e redefinição das relações estado-sociedade. Educação e sociedade, Campinas, v. 23, n. 80, set., 2002. p. 13-24.

PERONI, Vera Maria. Mudanças na configuração do Estado e sua influência na política educacional. In: PERONI, Vera; BAZZO; PEGORARO (Org.). Dilemas da Educação Brasileira em tempos de globalização neoliberal: entre o público e o privado. Porto Alegre: Editora da UFRGS, 2006.

TORRES, C. A. Estado, privatização e política educacional: elementos para uma crítica do neoliberalismo. In: GENTILI, Pablo. (Org.). Pedagogia da Exclusão: Crítica ao neoliberalismo em educação. Petrópolis: Vozes, 1995. p. 109-135.

TORRES, R. M. Melhorar a qualidade da educação básica? As estratégias do banco Mundial. In: TOMMASI, L.; WARDE, M. J.; HADDAD, S. (Org.). O Banco Mundial e as Políticas Educacionais. São Paulo: Cortez Editora, 1996. 